\title{
A COORDENAÇÃO PEDAGÓGICA: UMA PROPOSTA INTERDISCIPLINAR PARA A EDUCAÇÃO DE JOVENS E ADULTOS BASEADA NA EDUCAÇÃO PARA O TRABALHO
}

\author{
COORDINACIÓN PEDAGÓGICA: UNA PROPUESTA INTERDISCIPLINARIA PARA \\ LA EDUCACIÓN JUVENIL Y ADULTA BASADA EN LA EDUCACIÓN LABORAL
}

\author{
PEDAGOGICAL COORDINATION: AN INTERDISCIPLINARY PROPOSAL FOR \\ YOUTH AND ADULT EDUCATION BASED ON LABOR EDUCATION
}

\author{
Fernando Barcellos RAZUCK ${ }^{1}$ \\ Renata Cardoso de Sá Ribeiro RAZUCK ${ }^{2}$
}

RESUMO: Este artigo faz uma reflexão sobre o potencial transformador que a Coordenação Pedagógica (CP) tem na Educação. Essa reflexão é resultado de um trabalho de pesquisa realizado em uma Escola Pública de Ensino Médio, da Modalidade Jovens e Adultos (EJA), e tem como objetivo investigar as questões discutidas durante a $\mathrm{CP}$ e a sua articulação com o processo de ensino-aprendizagem. Tal reflexão fundamenta-se na Interdisciplinaridade e na Educação pelo Trabalho, que pode ser colocada em prática durante a Semana de Educação para a Vida. Entende-se assim que, a CP, ao abordar questões do cotidiano do aluno, remete à uma educação mais cidadã e inclusiva, levando ao debate de questões que abordem a sua realidade.

PALAVRAS-CHAVE: Coordenação pedagógica. Educação de jovens e adultos. Educação pelo trabalho. Interdisciplinaridade. Semana de educação para a vida.

RESUMEN: Este artículo reflexiona sobre el potencial transformador que la Coordinación Pedagógica (PC) tiene en Educación. Esta reflexión es el resultado de un trabajo de investigación realizado en una escuela secundaria pública, de la Modalidad de Jóvenes y Adultos (EJA), y tiene como objetivo investigar los temas discutidos durante el PC y su articulación con el proceso de enseñanza-aprendizaje. Dicha reflexión se basa en la interdisciplinariedad y la educación a través del trabajo, que se puede poner en práctica durante la Semana de la Educación para la Vida. Por lo tanto, se entiende que, al abordar cuestiones de la vida cotidiana del estudiante, se refiere a una educación más ciudadana e inclusiva, lo que lleva al debate de cuestiones que abordan su realidad.

PALABRAS CLAVE: Coordinación pedagógica. Educación de jóvenes y adultos. Educación a través del trabajo. Interdisciplinariedad. Semana de la educación para la vida.

\footnotetext{
${ }^{1}$ Secretaria de Educação do Distrito Federal (SEEDF), Brasília - DF - Brasil. Analista em Ciência e Tecnologia do Instituto de Radioproteção e Dosimetria. Coordenador do Programa Lato Sensu em Proteção Radiológica e Segurança de Fontes Radioativas. Doutor em Educação (UNB). ORCID: https://orcid.org/0000-0002-8416-4242. E-mail: razuckdabrasilia@hotmail.com

${ }^{2}$ Universidade Federal do Rio de Janeiro (UFRJ), Rio de Janeiro - RJ - Brasil. Professora Adjunta do Departamento de Didática. Doutora em Educação (UNB). ORCID: https://orcid.org/0000-0001-7841-3014. Email: razuckrenata@gmail.com
}

RPGE- Revista on line de Política e Gestão Educacional, Araraquara, v. 24, n. 2, p. 332-346, maio/ago., 2020. e-ISSN: 1519-9029. DOI: https://doi.org/10.22633/rpge.v24i2.13317 
ABSTRACT: This paper reflects on the transformative potential that the Pedagogical Coordination $(C P)$ has in Education. This reflection is the result of a research work carried out in a Public High School, of the Youth and Adults Modality (EJA, Portuguese initials), and aims to investigate the issues discussed during the CP and its articulation with the teachinglearning process. Such reflection is based on Interdisciplinarity and Education through Work, which can be put into practice during the Education for Life Week. Thus, it is understood that, when addressing issues of the student's daily life, it refers to a more citizen and inclusive education, leading to the debate of issues that address their reality.

KEYWORDS: Pedagogical coordination. Youth and adult education. Education through work. Interdisciplinarity. Education for life week.

\section{Introdução}

\section{A evolução histórica da coordenação pedagógica no Brasil}

De acordo com Gallon et al., em ambientes escolares é comum observar um grande distanciamento entre os saberes escolares daqueles do cotidiano dos estudantes, o que sugere uma pouca relação entre os conteúdos desenvolvidos na escola e o contexto discente, contribuindo para que o estudante pense a escola como desinteressante. Porém, ainda segundo os autores, trabalhos com vieses interdisciplinares promovem conexões entre situações apresentadas pelo estudante e os conteúdos das diferentes disciplinas envolvidas.

Esta contextualização, por meio da interdisciplinaridade, acaba por produzir novos significados. Nessa perspectiva, o desenvolvimento de trabalhos interdisciplinares pode ser realizado durante a coordenação pedagógica $(\mathrm{CP})$, que ocupa papel decisivo tanto nas questões pedagógicas quanto burocráticas da escola. Assim, a CP seria responsável por três aspectos do fazer docente: formação, articulação e incentivo.

Assim, para Fernandes (2011), a CP pode ser vista como uma forma inovadora de participação docente na gestão, capaz de ampliar as possibilidades de trabalho coletivo e de articulação pedagógica. Esta participação pode ser tão significativa a ponto de possibilitar a democratização da escola, alterando, inclusive, as rígidas estruturas de administração escolar, auxiliando nas reformas educacionais. Assim, para a autora, de maneira geral, a CP reivindica historicamente o papel de articulador pedagógico, gerenciando as reformas necessárias para a implantação das medidas inovadoras.

Ou seja, a CP exerce um papel de extrema importância dentro da escola, sendo a sua atividade de fundamental relevância, não só na execução da rotina escolar, mas também na elaboração de atividades que visem à melhoria da qualidade do ensino, auxiliando no processo de democratização escolar democratização esta, não só de cunho político-pedagógico, mas também de 
saberes, tornando-se assim um espaço/tempo de planejamento e de organização das atividades educativas que fazem parte da rotina escolar. Portanto, coordena, acompanha, assessora, apoia e avalia as atividades pedagógico-curriculares. Sua atribuição prioritária é prestar assistência pedagógico-didática aos professores em suas respectivas disciplinas no que diz respeito ao trabalho interativo com os alunos. Há lugares onde a coordenação se restringe à disciplina em que o coordenador é especialista; em outros, a coordenação atende a todas as disciplinas. Outra atribuição do coordenador pedagógico é o relacionamento com os pais e com a comunidade, especialmente no que se refere ao funcionamento pedagógico-curricular e didático da escola, à comunicação das avaliações dos alunos e à interpretação feita delas (LIBÂNEO; OLIVEIRA; TOSCHI, 2014, p. 466).

Moehlecke (2017), ao fazer um levantamento sobre a definição do termo e papel da CP ao longo da educação no Brasil, verificou a existência de uma grande variedade de expressões e nomenclaturas utilizadas para designar diferentes funções criadas para a ação junto à gestão das escolas. Segundo a autora, a própria LDB/96 utiliza os termos inspeção, supervisão e orientação educacional para se referir ao profissional da educação que atua nas funções de orientação e CP, expressões que também ganham contornos locais nas legislações de estados e municípios.

Moehlecke (2017) faz ainda uma avaliação histórica dos termos relacionados à CP, bem como a sua evolução ao longo do tempo para as suas atribuições, de acordo com o pensamento educacional vigente à época no Brasil (quadro 1). Assim, essa função remonta à experiências educacionais da década de 20, com os primeiros registros legais nacionais na década de 30.

Quadro 1 - Evolução do papel do coordenador pedagógico no Brasil

\begin{tabular}{|c|c|c|c|}
\hline Período & Marco Legal & Função & Características \\
\hline Década de 1930 & $\begin{array}{l}\text { Decretos-Lei no. } \\
\text { 19.890/31 e no. } \\
21.241 / 32 \text { (reforma } \\
\text { Francisco Campos) }\end{array}$ & $\begin{array}{l}\text { Inspetor Escolar - atuava no } \\
\text { controle e fiscalização das } \\
\text { normas prescritas pelos órgãos } \\
\text { centrais superiores junto às } \\
\text { escolas de ensino secundário e } \\
\text { às práticas pedagógicas dos } \\
\text { seus professores. O papel do } \\
\text { inspetor escolar seria exercido } \\
\text { por professores escolhidos } \\
\text { entre os considerados bem- } \\
\text { sucedidos e com ampla } \\
\text { experiência educacional. }\end{array}$ & $\begin{array}{l}\text { Concepção de escola } \\
\text { neutra, baseada na } \\
\text { hierarquização de funções } \\
\text { e tarefas, com um } \\
\text { currículo único, } \\
\text { centralizado e } \\
\text { homogeneizador de } \\
\text { competências e hábitos } \\
\text { que destituía o professor } \\
\text { de sua capacidade } \\
\text { reflexiva e criativa, dentro } \\
\text { de uma dicotomia do fazer } \\
\text { pedagógico. }\end{array}$ \\
\hline Década de 1970 & $\begin{array}{l}1^{\circ} \text { Estatuto do } \\
\text { Magistério, de 1974, } \\
\text { tendo suas atribuições } \\
\text { definidas nos } \\
\text { Decretos-Lei no } \\
5586 / 75 \text { e } n^{\circ} 7510 / 76 .\end{array}$ & $\begin{array}{l}\text { Supervisor Pedagógico - } \\
\text { fortemente associado à } \\
\text { fragmentação do trabalho } \\
\text { escolar, dentro de uma rígida } \\
\text { hierarquia de poder dentro da } \\
\text { escola. }\end{array}$ & $\begin{array}{l}\text { Recrudescimento da } \\
\text { concepção tecnicista da } \\
\text { educação, intensificando a } \\
\text { divisão do trabalho } \\
\text { pedagógico. Enfatiza-se } \\
\text { ainda mais a separação } \\
\text { entre } \\
\text { concepção/planejamento e }\end{array}$ \\
\hline
\end{tabular}




\begin{tabular}{|c|c|c|c|}
\hline & & & $\begin{array}{l}\text { execução, entre as funções } \\
\text { dos gestores escolares e o } \\
\text { trabalho dos professores } \\
\text { em sala de aula. Cabia aos } \\
\text { especialistas em educação } \\
\text { definir metodologias e } \\
\text { apostilas didáticas, sem } \\
\text { discussão ou consulta aos } \\
\text { docentes, além de } \\
\text { fiscalizar sua aplicação em } \\
\text { sala de aula. }\end{array}$ \\
\hline Década de 1980 & $\begin{array}{l}\text { Constituição Federal } \\
\text { de } 1988 \text { e Lei de } \\
\text { Diretrizes e Bases da } \\
\text { Educação de } 1996 .\end{array}$ & $\begin{array}{l}\text { Coordenador Pedagógico - } \\
\text { Um novo perfil de profissional } \\
\text { começa a ocupar esse espaço, } \\
\text { com distintas funções dentro } \\
\text { de uma proposta de gestão } \\
\text { democrática das relações intra } \\
\text { e extra escolares, conforme } \\
\text { preconizado, apesar de suas } \\
\text { limitações regulatórias. Nesse } \\
\text { momento, o coordenador } \\
\text { pedagógico ganha o papel de } \\
\text { articulador e formador, } \\
\text { voltado ao trabalho de ensino- } \\
\text { aprendizagem junto aos } \\
\text { docentes e aos processos de } \\
\text { gestão, dentro de uma } \\
\text { proposta de construção pela } \\
\text { escola, de forma coletiva e } \\
\text { participativa, de seu projeto } \\
\text { político e pedagógico, } \\
\text { envolvendo professores, } \\
\text { alunos, pais, funcionários, } \\
\text { comunidade. }\end{array}$ & $\begin{array}{l}\text { As expectativas quanto a } \\
\text { sua atuação envolvem a } \\
\text { superação da antiga } \\
\text { divisão do trabalho escolar } \\
\text { e a dicotomia entre } \\
\text { pensar/planejar e } \\
\text { fazer/executar. Ainda que } \\
\text { algumas experiências } \\
\text { educacionais nos anos } 60 \\
\text { tenham tensionado esse } \\
\text { modelo de gestão, mesmo } \\
\text { que de forma pontual, } \\
\text { como os ginásios } \\
\text { vocacionais e as escolas } \\
\text { experimentais, foi somente } \\
\text { no contexto de } \\
\text { redemocratização do país, } \\
\text { nos anos 1980, que a } \\
\text { função de coordenador } \\
\text { pedagógico ganhou maior } \\
\text { abrangência com relações } \\
\text { de poder mais horizontais } \\
\text { e descentralizadas. }\end{array}$ \\
\hline
\end{tabular}

Fonte: Moehlecke (2017)

\section{O papel do coordenador pedagógico}

A partir do quadro 1, pode-se observar que, historicamente, a identidade do coordenador pedagógico se divide em dois momentos: antes e depois da Lei de Diretrizes e Bases - LDB (Lei no 9394/96). Essa mudança deve-se, principalmente, ao princípio democrático citado no artigo $3^{\circ}$, inciso VII, que garante a gestão democrática do ensino público, na forma da lei e da legislação dos sistemas de ensino.

Com respeito à função do coordenador pedagógico, a sua origem está vinculada à supervisão escolar, acompanhando a ação educativa desde que a escola institucionalizou-se, ainda no período colonial. Assim, somente a partir da década de 1920, por meio de algumas reformas educacionais de âmbito nacional, que a função supervisora foi se consolidando como categoria profissional, assumindo uma dimensão menos administrativa e mais técnica de acompanhamento sistemático do trabalho docente (ALVES, 2013; LIMA, 2016). 
Neste sentido, Alves (2013) aponta que, antes da LDB, o papel do coordenador era autoritário, controlador, atuando mais para inspeção da escola do que na contribuição para a construção de um saber pedagógico desafiador; já posterior à lei, a função é democrática e dá grande ênfase ao coletivo, tendo que se pensar de forma crítica e reflexiva, o que consequentemente acaba por atingir o processo de ensino-aprendizagem dos alunos.

Assim, durante o percurso histórico da função, o supervisor escolar exerceu função, ora de controle, ora de articulação pedagógica, até se definir a presença do coordenador pedagógico, delimitando seu espaço de atuação no ambiente escolar (LIMA, 2016).

Atualmente, considerando o princípio da gestão democrática, seguindo a Portaria no 27 , de 2 de fevereiro de 2012, capítulo II, artigo 16 c, o coordenador pedagógico das escolas públicas deve ser escolhido (eleito pelos professores da unidade escolar), e não indicado indiretamente (LIMA, 2016).

Apesar de ser uma prática democrática, a escolha do coordenador acaba gerando um certo desafio na escola, uma vez que o coordenador é um professor que "está" coordenando, sem que necessariamente haja um treinamento ou formação específica para isso, de modo que, na maioria das vezes, a identidade da função não se enquadra nas suas atribuições, já que acaba assumindo papeis que não são pertinentes à prática pedagógica, como, por exemplo, no auxílio às funções administrativas da escola, gerando uma certa ambiguidade em sua identidade, bem como na indefinição de seu papel e espaços de atuação.

Logo, executa papéis que variam entre os sistemas de ensino, principalmente de acordo com suas concepções de gestão educacional. Na prática, as funções do coordenador têm oscilado entre a articulação escolar e a coordenação acadêmica, de modo colaborativo e de supervisão e de controle e técnico-administrativo. Porém, pode ser também uma figura chave para garantir uma autonomia relativa da escola e da produção docente, de modo a construir e executar efetivamente seu projeto político pedagógico de modo participativo (LIMA, 2016; MOEHLECKE 2017).

\section{Fundamentação teórica - atividades interdisciplinares e educação pelo trabalho}

De acordo com Hartmann e Zimmermann (2007), a interdisciplinaridade caracteriza-se por atividades pedagógicas organizadas a partir da interação entre os docentes, que aconteceriam por meio do diálogo, em busca de conexões entre os objetos de conhecimento das disciplinas. Assim, fazer interdisciplinaridade na escola não se limitaria apenas a promover as condições para que o estudante estabeleça relações entre informações para construir um saber 
integrado, mas também consiste em estabelecer e manter o diálogo entre professores de diferentes disciplinas com o objetivo de estabelecer um trabalho integrado entre eles.

Logo, a integração de conhecimentos disciplinares e o desenvolvimento de competências seria o mais importante. A interdisciplinaridade ganha importância então à medida que os docentes passam a desenvolver um trabalho pedagógico de forma integrada, levando o estudante a comunicar-se, argumentar, enfrentar problemas de diferentes naturezas e a elaborar críticas ou propostas de ação em torno de questões abrangentes da atualidade, utilizando como ferramenta o conhecimento escolar.

Assim, seria possível ao professor de uma disciplina desenvolver temáticas com uma perspectiva entre áreas sem a necessidade de fazer um acordo interdisciplinar com outros colegas, além de ter a função de aproximar docentes de diferentes disciplinas de modo a diminuir o distanciamento entre as duas culturas presentas nas escolas - no caso, a científica e a humanista. Como consequência, a aproximação entre estas culturas promoveria a uma maior interação, não só entre professores e professores, mas também entre professores e alunos, o que pode auxiliar na compreensão do ponto de vista do outro.

E uma forma de se realizar a interdisciplinaridade na escola seria por meio de oficinas temáticas, que viriam a ser, segundo da Silva et al., (2008) um processo de trabalho real, propiciando a articulação entre o trabalho manual e intelectual, sem necessariamente estar atrelado ao mercado de trabalho.

Para os autores, tendo como base Vigotski (2003), o trabalho seria a própria base do processo educativo, ou seja, a própria matéria-prima da educação, e não apenas visto como um tema, método ou meio de ensino, introduzindo assim não apenas o trabalho na escola, mas também a escola no trabalho, uma vez que a educação pelo trabalho é um processo comum entre os seres e que requer a coordenação dos esforços e a regulação das próprias reações para o melhor convívio coletivo. Logo,

Para compreender o significado psicológico desse fato é preciso lembrar que a educação pelo trabalho promove métodos didáticos de ensino totalmente novos. O método anterior, denominado acromático, de simples transmissão de conhecimento do professor para o aluno, assim como o método erotemático, isto é, o método de descoberta conjunta do conhecimento pelo professor e pelo aluno por meio de perguntas, bem como o método heurístico, ou seja, a busca dos conhecimentos pelos próprios alunos, todos eles em conjunto não abrangem a essência pedagógica da educação pelo trabalho (VIGOTSKI, 2003, p. 189). 


\section{Metodologia}

Este artigo faz então uma reflexão sobre o potencial transformador que a $\mathrm{CP}$ tem na Educação. Essa reflexão é resultado de um trabalho de pesquisa realizado em uma Escola Pública de Ensino Médio, da Modalidade Jovens e Adultos (EJA), de uma região administrativa (cidade satélite) de Brasília (Distrito Federal), e tem como objetivo investigar as questões discutidas durante a CP e a sua articulação com o processo de ensino-aprendizagem.

Assim, este trabalho tem como objetivo relatar os resultados obtidos em experiências didáticas por meio de oficinas realizadas durante a Semana de Educação para a Vida, tendo como eixo estruturador a educação para o trabalho, na perspectiva da interdisciplinaridade.

Tal reflexão fundamenta-se na Educação pelo Trabalho, que tem por base a teoria da Psicologia histórico-cultural de Vigotski, e no processo interdisciplinar de construção do conhecimento.

Para isso, foi acompanhado o trabalho pedagógico de uma escola durante um (1) ano, observando como as práticas pedagógicas com enfoque na educação pelo trabalho geraram frutos, principalmente durante a execução de atividades pedagógicas previstas no calendário escolar, nos dia temático sobre a Educação para a Vida, quando atividades com caráter interdisciplinar foram executadas por meio de oficinas.

Também se examinou como se organiza o trabalho interdisciplinar no Ensino Médio, identificando os fatores que tornam possível a integração entre as disciplinas das áreas de ciências naturais e ciências humanas.

\section{Resultados e discussão}

\section{A CP no Distrito Federal}

Pode-se dizer que no Distrito Federal o espaço para $\mathrm{CP}$ passou por várias transformações, conforme mostrado abaixo (QUADRO NEGRO, 2014):

- até 1995 - o coordenador não era dispensado da regência de classe, ou seja, atuava em sala de aula e ainda coordenava as ações pedagógicas. Porém, neste mesmo ano, a Secretaria de Educação do DF promoveu a formação de professores para atuarem como coordenadores pedagógicos, visando implementar a Escola Candanga;

- 1995 - começa a formação com o curso Vira Brasília Educação. Professores fazem curso para atuarem na CP. Nesta época, o cargo de coordenador era não-oficial, porque tinham duas turmas, não havia liberação de regência. Eleições para direções e conselhos escolares; 
- 1996 - os professores com carga horária de 40 horas semanais na mesma escola puderam atuar com $20 \mathrm{~h}$ em regências e $20 \mathrm{~h}$ como coordenador pedagógico;

- 1997 - os professores passaram a ser liberados das 40h para atuar apenas como coordenador. Por opção, algumas escolas aderiram à Escola Candanga, primeira fase (somente turmas de alfabetização), "enturmação" por idade, com jornada ampliada, não havia folga de coordenação. Coordenadores poderiam ficar 20h liberados para atuar como coordenadores e $20 \mathrm{~h}$ em regência. Novas escolas entram na primeira fase da Escola Candanga, continuam cursos de formação. Outras iniciam a segunda fase que abrange as turmas de $3^{\circ}, 4^{\circ}$ e $5^{\circ}$ séries (atualmente $4^{\circ}, 5^{\circ}$ e $6^{\circ}$ Ano). Eleições para direção e conselhos escolares. Coordenadores são liberados 40h para atuar na coordenação;

- 1998 - instituição da jornada ampliada;

- 1999 - mudança de governo atrasa a implantação da jornada ampliada;

- 2000 - universalização da jornada ampliada;

- 2008 - com a promulgação da Lei Nacional do Piso do Magistério (Lei 11.738/08), um terço da carga horária do professor foi destinada à coordenação pedagógica. No DF, a jornada de coordenação pedagógica é maior e o coordenador tem justamente a tarefa de otimizar este tempo de planejamento e formação do professor.

Atualmente, de acordo com a portaria $n^{\circ} 561$ de 2017, que dispõe sobre os critérios referentes à atuação dos servidores integrantes da Carreira Magistério Público do Distrito Federal nas atividades de docência e na orientação educacional, em seu artigo $5^{\circ}$, é dito que os professores podem ter as seguintes cargas horárias e respectivas horas de coordenação pedagógica:

I - quarenta horas semanais, em jornada ampliada, no turno diurno, sendo três horas em coordenação pedagógica, diárias, perfazendo vinte e cinco horas em regência de classe e quinze horas em CP;

II - quarenta horas semanais, no regime de vinte mais vinte horas, sendo quatro horas em coordenação pedagógica, por turno, em dois dias da semana, perfazendo doze horas em regência de classe e oito horas em $\mathrm{CP}$; e

III - vinte horas semanais, nos turnos matutino, vespertino ou noturno, quatro horas em $\mathrm{CP}$ em dois dias da semana, perfazendo doze horas em regência de classe e oito horas em coordenação pedagógica.

Na mesma portaria é definido, em seu capítulo II, o desenvolvimento das atividades de $\mathrm{CP}$, em seu capítulo III as atribuições e requisitos para o exercício do coordenador pedagógico 
local e em seu capítulo IV o quantitativo de coordenadores pedagógicos locais por unidade escolar.

Assim, os professores são organizados para o cumprimento de sua jornada de trabalho em três dias de coordenação semanal: um dia de coordenação coletiva, um dia de coordenação por área de conhecimento e um dia de coordenação individual, sendo este o dia que cada um pode cumprir fora do ambiente da escola, em outros espaços de formação continuada. O único dia da semana em que todos estão na escola é a quarta-feira, quando acontece a coordenação pedagógica coletiva.

Resumidamente, com relação à organização da CP nas escolas do DF (anos finais), que é objeto deste trabalho (no caso, para o EJA), a distribuição dos dias está resumida no quadro 2.

Quadro 2 - Organização da coordenação pedagógica nas escolas do DF (anos finais)

\begin{tabular}{|c|c|c|}
\hline Dia da Semana & Área de Conhecimento & Disciplinas \\
\hline Segunda-feira & Individual & Livre para o professor realizar suas atividades \\
\hline Terça-feira & Ciências da Natureza & Matemática, Biologia, Física e Química \\
\hline Quarta-feira & Coletiva & Todas as disciplinas \\
\hline Quinta-feira & Linguagens e Códigos & $\begin{array}{l}\text { Língua Portuguesa, Língua Estrangeira, } \\
\text { Educação Física e Arte }\end{array}$ \\
\hline Sexta-feira & Ciências Humanas & História, Geografia e Sociologia \\
\hline Segunda-feira & Individual & Livre para o professor realizar suas atividades \\
\hline
\end{tabular}

Fonte: Elaborado pelo autor.

Portanto, na rede pública de ensino do Distrito federal a CP está consolidada desde a década de 1990. O coordenador pedagógico é aquele que tem a função de organizar este espaço/tempo de modo que se configure como um efetivo espaço de formação continuada docente, devendo promover encontros de estudo e debate de questões necessárias a uma nova organização da escola. Apesar desta importância didática, os coordenadores têm formação inicial em diferentes áreas do conhecimento, não havendo uma formação exigida ou um treinamento oferecido para a realização da função (LIMA, 2016).

Atualmente, o coordenador pedagógico tem por finalidade planejar, orientar, acompanhar e supervisionar as atividades didático-pedagógicas, promovendo ações que contribuam para a implementação do currículo em vigor nas escolas. O planejamento e realização da CP são de responsabilidade dos integrantes da diretoria de cada instituição de ensino, em colaboração com os próprios coordenadores e a equipe de professores (QUADRO NEGRO, 2014). 
Além disso, o coordenador tem importante função na escola: articular os saberes entre todos os sujeitos envolvidos no eixo escolar e favorecer o coletivo e suas relações desde a escola e a família até as relações entre o aluno e o professor. Segundo o Regimento Interno da SEEDF, art. 21 (DISTRITO FEDERAL, 2009), o coordenador pedagógico tem como funções:

I - participar da elaboração, da implementação, do acompanhamento e da avaliação da Proposta Pedagógica da instituição educacional;

II - orientar e coordenar a participação docente nas fases de elaboração, de execução, de implementação e de avaliação da Proposta Pedagógica da instituição educacional;

III - articular ações pedagógicas entre professores, equipes de direção e da Diretoria Regional de Ensino, assegurando o fluxo de informações;

IV - divulgar e incentivar a participação dos professores em todas as ações pedagógicas promovidas pela instituição educacional, pela Diretoria Regional de Ensino e pela Subsecretaria de Educação Básica, inclusive as de formação continuada;

V - estimular, orientar e acompanhar o trabalho docente na implementação das Orientações Curriculares da Secretaria de Estado de Educação do Distrito Federal, por meio de pesquisas, de estudos individuais e em equipe e de oficinas pedagógicas locais;

VI - divulgar, estimular e propiciar o uso de recursos tecnológicos, no âmbito da instituição educacional, com as orientações metodológicas específicas;

VII - orientar os professores recém-nomeados e recém-contratados quanto ao desenvolvimento da Proposta Pedagógica;

VIII - propor reflexão avaliativa da equipe, objetivando redimensionar as ações pedagógicas; e

IX - propor ações educativas que visem ao avanço de estudos e a recuperação do processo de ensino e aprendizagem.

\section{A semana da educação para a vida}

A Semana de Educação para a vida é uma Lei de nº 11.988 , datada em 27 de julho de 2009, sancionada pela Presidência da república, Casa Civil, subchefia de Assuntos Jurídicos. Foi decretada pelo Congresso Nacional para ser realizada nas escolas públicas de ensino fundamental e médio de todo o País. Deverá ser realizada em um período determinado pelas Secretarias de Educação, em Calendário Escolar, e ser aberta para pais, alunos e comunidade em geral. 
O objetivo desta Lei é ministrar conhecimentos relativos a matérias não constantes do currículo obrigatório, tais como: Ecologia e Meio Ambiente, Educação para o Trânsito, Sexualidade, Prevenção contra Doenças Transmissíveis, Direito do Consumidor, Estatuto da Criança e do Adolescente, etc. Tais assuntos serão ministrados através de seminários, palestras, exposições-visita, projeções de slides, filmes ou qualquer outra forma não convencional. Fazse necessário também, que os convidados para ministrar os conteúdos pussuam nível comprovado de conhecimento sobre os assuntos abordados.

Criada pela Lei n ${ }^{\circ} 11.988 / 2009$, a Semana de Educação para a Vida instituiu que em todas as escolas de ensino fundamental e médio da rede pública no país - em períodos a serem determinados pelas respectivas Secretarias Estaduais de Educação - deverão ministrar, durante uma semana, atividades relacionadas aos conhecimentos relativos às matérias não constantes do currículo obrigatório, para a discussão de temas concernentes à realidade dos alunos, conforme consta no artigo $2^{\circ}$ da lei:

A atividade escolar aludida no art. 1o desta Lei terá duração de 1 (uma) semana e objetivará ministrar conhecimentos relativos a matérias não constantes do currículo obrigatório, tais como: ecologia e meio ambiente, educação para o trânsito, sexualidade, prevenção contra doenças transmissíveis, direito do consumidor, Estatuto da Criança e do Adolescente, etc. (BRASIL, 2009, p. 1).

Nesse sentido, durante o ano letivo, nas reuniões pedagógicas, foram levantados temas que abordassem questões do cotidiano do aluno e que poderiam ser oferecidas pelos professores durante a Semana. Participaram das reuniões pedagógicas, para sugestão dos temas, além do coordenador pedagógico, o diretor da escola, o orientador educacional e mais dezoito docentes, das respectivas disciplinas: Física (3), Química (3), Biologia (2), Matemática(4), Educação Física (1), Filosofia (1), História (1), Geografia (1), Sociologia (1), Inglês (1), Artes (1) e Português (4).

Durante as coordenações pedagógicas, além da discussão de questões do cotidiano da escola, era promovido pelo coordenador pedagógico, e pelo Diretor da escola, o debate de questões que poderiam ser levantadas para a Semana de Educação para Vida, e de como estas temáticas poderiam ser ofertadas de forma interdisciplinar, ou seja, com o envolvimento de mais de uma disciplina, na forma de oficina temática, durante a Semana. Isto porque a Semana já se mostrou como uma ótima oportunidade de desenvolver atividades interdisciplinares na EJA (RAZUCK; RAZUCK, 2012).

A princípio, foram propostas algumas atividades diretamente relacionadas ao mundo do trabalho, ou seja, oficinas aplicáveis ao cotidiano social dos alunos. Assim, foram 
desenvolvidas as seguintes oficinas, com a participação dos respectivos docentes de diferentes disciplinas: Jogos Matemáticos (Matemática), História do Negro na Sociedade (Filosofia e Sociologia), Armas Químicas (Biologia e Química), Leitura e Produção de Poemas (Português), Produção de Maquetes (Artes), Doenças Sexualmente Transmissíveis (Biologia) e Tradução de Músicas para o Português (Inglês e Português).

Para o Diretor H., a importância da coordenação pedagógica não está somente no aspecto administrativo da escola, uma vez que a coordenação tem também a função de informar e discutir com os professores assuntos relativos à dinâmica da escola, mas também para promover o aspecto pedagógico e interativo entre os professores:

É durante a coordenação que podemos passar para os professores os assuntos internos da escola, mas também serve como um canal de comunicação entre a direção da escola e os professores, e com os professores entre si, Isto porque tem professor que só se encontra na escola durante a coordenação, já que as vezes dão aula em horários diferentes e não dá tempo de conversar durante os intervalos de aula (Diretor $\mathrm{H})$.

Para o coordenador F., a coordenação serve não só para acompanhar o andamento das disciplinas, mas também para promover a interdisciplinaridade, seja por meio dos simulados, que envolvem questões de todas as disciplinas, seja por meio dos dias ou semanas temáticas, como a própria Semana de Educação para a Vida, já que podem favorecer a discussão de assuntos que vão além do conteúdo passado em sala de aula:

Com certeza a coordenação pedagógica facilita muito o andamento curricular da escola, pois dá para entender como os professores visualizam as suas disciplinas, e de que maneira uma disciplina pode contribuir no aprendizado da outra. E os dias temáticos têm um papel fundamental, pois dão a liberdade para o professor desenvolver conteúdos que vão além do que está na programação curricular da matéria dele (Coordenador F).

Já para a aluna S, de 47 anos, a Semana serve para aprender mais sobre as matérias, além de se ser uma forma de se aproximar mais dos professores:

Ah, participando das oficinas até me ajudou mais a entender a Matemática e a Sociologia, que são muito difíceis, têm muita informação, e vão muito além do meu dia-a-dia. Agora deu até para entender como estas matérias fazem parte da minha vida. Deu até para ver que o professor também é humano, deu outra visão dele, pois eles ficam muito mais leves na Semana do que na sala de aula. E sempre tem festa, lanches, a gente se envolve muito mais com a escola (Alina S). 


\section{Considerações finais}

Pode-se observar, neste trabalho, que a importância do coordenador e da $\mathrm{CP}$ vêm crescendo de forma diretamente proporcional à crescente demanda escolar. $\mathrm{O}$ coordenador pedagógico se envolve cada vez mais com os professores de todas as disciplinas a fim de favorecer o processo de ensino-aprendizagem. Ou seja, acaba por atuar como um mediador, adotando um perfil dialógico e reflexivo, levando toda a escola a pensar na sua prática diária, valorizando sempre as ações coletivas, vinculadas ao projeto pedagógico da escola, relacionado à função social da escola.

E uma forma de desenvolver e aprimorar o projeto pedagógico da escola, que tem como objetivo principal atender as perspectivas e demandas da comunidade escolar na luta por uma educação de qualidade, seria por meio dos dias temáticos. Isto porque acaba por envolver toda comunidade escolar, superando os obstáculos que inviabilizam as ações coletivas, ao abordar questões da realidade social do aluno, convidando-o a debater, junto com a escola, ações que venham a interferir diretamente no seu processo educativo.

Assim, a Semana de Educação para a Vida, que faz parte do calendário oficial escolar, tem como principal objetivo ministrar conhecimentos relativos a matérias não constantes do currículo obrigatório. Com isso, oferece a liberdade aos professores e à escola de se aproximar mais do seu aluno, levando a repensar e aprimorar o seu papel social e formador.

Além disso, a prática de abordar temas relacionados ao cotidiano do aluno, por meio de oficinas, se apresenta como uma interessante estratégia de ensino, pois superam o ensino tradicional, uma vez que adota o mundo do trabalho como eixo norteador, tendo como objetivo melhorar a aprendizagem dos conteúdos escolares, servindo como eixo articulador entre a escola e a realidade dos alunos, uma vez que aborda aprendizado com caráter prático e crítico.

E, por meio da interdisciplinaridade, observou-se que os docentes trabalharam temas sociais, aproximando as culturas científica e humanista, característico da interdisciplinaridade, como um instrumento de aproximação entre docentes e alunos, uma vez que envolve a troca de conhecimentos escolares e sociais, tendo como foco comum a aprendizagem. Pode ainda ser vista como uma prática política, pois remete à negociação entre diferentes pontos de vista a fim de alcançar os conteúdos disciplinares a serem trabalhados de forma coletiva.

Entende-se assim que, a CP, ao abordar questões do cotidiano do aluno, remete à uma educação mais cidadã e inclusiva, levando ao debate de questões que abordem a sua realidade. 


\section{REFERÊNCIAS}

ALVES, M. R. O coordenador pedagógico como facilitador do processo de alfabetização. 2013. Monografia (Trabalho de Conclusão de Curso de Especialização em Coordenação Pedagógica) - Escola de Aperfeiçoamento de Profissionais da Educação, Universidade de Brasília, Brasília, 2013.

BRASIL. Lei n. 11.988, de 27 de julho de 2009. Cria a Semana de Educação para a Vida, nas escolas públicas de ensino fundamental e médio de todo o País, e dá outras providências.

Diário Oficial da União, Brasília, 28 jul. 2009.

DA SILVA, R. R.; RAZUCK, R. C. S. R.; TUNES, E. Desafios da escola atual: a educação pelo trabalho. Química Nova, v. 31, n. 2, 452-461, 2008.

DISTRITO FEDERAL. Secretaria de Estado de Educação. Regimento Interno da Secretaria de Estado de Educação do Distrito Federal, 1. ed. Brasília, 2009.

DISTRITO FEDERAL. Portaria n. 27, de 2 de fevereiro de 2012. Diário oficial do Distrito Federal, Poder Executivo, Brasília, DF, n. 27, Seção 1, p.11-14, 06 fev. 2012.

FERNANDES, M. J. S. A coordenação pedagógica nas escolas estaduais paulistas: resoluções recentes e atuação cotidiana na gestão e organização escolar. RBPAE, v. 27, n. 3, p. 361-588, set./dez. 2011.

GALLON, M. da S.; FILHO, J. B. R.; MACHADO, J. A. Desafios à realização da interdisciplinaridade no ambiente escolar: perspectivas dos docentes e da coordenação pedagógica. Revista Thema, v. 14, n. 4, 2017.

HARTMANN, A. M.; ZIMMERMANN, E. O trabalho interdisciplinar no Ensino Médio: a reaproximação das “DuasCulturas". Revista Brasileira de Pesquisa em Educação em Ciências, v. 7, n. 2, 2007.

LIBÂNEO, J. C.; OLIVEIRA, J. F. de; TOSCHI, M. S. Educação Escolar: política, estrutura e organização. 10. ed. São Paulo: Cortez, 2014.

LIMA, S. M. G. O coordenador pedagógico e seu processo formativo: perspectivas e limites de trabalho. Orientadora: Cleide Maria Quevedo Quixadá Viana. 2016. 149 f. Dissertação (Mestrado em Educação) - Universidade de Brasília, Brasília, 2016.

MOEHLECKE, S. O coordenador pedagógico nos sistemas de ensino do Rio de Janeiro: uma nova aposta na gestão das escolas? RBPAE, v. 33, n. 1, p. 223-239, jan./abr. 2017.

QUADRO NEGRO. Informativo do Sindicato dos Professores no Distrito Federal. Construindo a Educação - Coordenador Pedagógico. Ano XXXV, n. 184, fev. 2014.

RAZUCK, F. B.; RAZUCK, R. C. S. R. O combate ao tabaco na escola: a interferência da indústria tabagista. Revista de Ensino de Biologia da Associação Brasileira de Ensino de Biologia (SBEnBio), v. 5, p. 1, 2012. 
VIGOTSKI, L. S. O Esclarecimento Psicológico da Educação pelo Trabalho. Porto Alegre: Psicologia Pedagógica, Artmed, 2003.

\section{Como referenciar este artigo}

RAZUCK, Fernando Barcelos; RAZUCK; Renata Cardoso de Sá Ribeiro. A coordenação pedagógica: uma proposta interdisciplinar para a educação de jovens e adultos na educação para o trabalho. Revista on line de Política e Gestão Educacional, Araraquara, v. 24, n. 2, p. 332346, maio/ago., 2020. e-ISSN: 1519-9029. DOI: https://doi.org/10.22633/rpge.v24i2.13317

Submetido em: 10/11/2019

Revisões requeridas: $18 / 12 / 2019$

Aprovado em: 20/01/2020

Publicado em: 09/04/2020 